\title{
Quality improvement in neurology
}

\section{Neuro-otology quality measurement set}

Habib Rizk, MD, MSc, Yuri Agrawal, MD, MPH, Susan Barthel, Marc L. Bennett, MD, MMHC, Joni K. Doherty, MD, PhD, Patricia Gerend, Daniel R. Gold, DO, David Morrill, John G. Oas, MD, J. Kirk Roberts, MD, Erika Woodson, MD, David A. Zapala, PhD, Amy Bennett, JD, and Anant M. Shenoy, MD

Correspondence Amy Bennett quality@aan.com

Neurology ${ }^{\circledR}$ 2018;91:697-701. doi:10.1212/WNL.0000000000006217

Disorders that lead to dizziness and balance problems of a peripheral or central vestibular origin are treated by specialists within the field of neuro-otology. An estimated 90 million Americans aged $\geq 17$ years ( $42 \%$ of the current population) experience dizziness at least once in their lifetime. ${ }^{1}$ Vestibular vertigo is prevalent, with $8.4 \%$ of US adults (approximately 18 million people) affected. ${ }^{2}$ Dizziness causes a significant effect on work productivity, with $51 \%$ absenteeism and loss of productivity and $12 \%$ complete disability. ${ }^{3}$

The American Academy of Neurology Institute (AANI) and American Academy of Otolaryngology-Head and Neck Surgery (AAO-HNSF) noted a need for quality measures focused on improving outcomes for patients diagnosed with neuro-otologic conditions causing dizziness and balance problems. A multidisciplinary work group consisting of representatives of various stakeholders (including neuro-otologists, neurologists, audiologists, and patient support groups) was formed to that effect. It approved 5 measures focusing on benign paroxysmal positional vertigo (BPPV), Ménière disease, vestibular migraine, and unilateral vestibular hypofunction (table). Full measurement specifications are available online at aan.com/practice/quality-measures/ and in appendix e-1 (links.lww.com/WNL/A678).

\section{Opportunities for improvement}

The work group initially identified 21 potential concepts for measurements. After prioritizing concepts that are supported by strong evidence and guideline statements, are feasible to collect, do not have existing quality measures, and have a known link to improved health care outcomes, the work group settled on 5 measures to develop. The 5 measures address (1) the quality of life of patients with a neuro-otology condition causing dizziness and balance problems, (2) the role of vestibular rehabilitation in vestibular hypofunction, (3) the use of the Dix-Hallpike maneuver, (4) the use of the canalith repositioning procedure (CRP; also known as the Epley maneuver) in BPPV, and (5) standard BPPV management.

Dizziness has a meaningful effect on quality of life. Patients with dizziness are more likely to report poor health, depression, less confidence in performing activities of daily living, and an overall reduced quality of life on patient-reported outcome measures (PROMs). ${ }^{4}$ PROMs are usually collected via questionnaires and these are not routinely administered in most practices. Patients and caregivers have signaled that this information is of value to them, and the Centers for Medicare and Medicaid Services (CMS) has recently signaled a plan to incorporate PROMs data, such as quality of life assessments, into their Merit-based Incentive Payment System (MIPS). ${ }^{5}$

From the Otology-Neurotology Division, Department of Otolaryngology-Head and Neck Surgery (H.R.), Medical University of South Carolina, Charleston; Departments of Otolaryngology-Head and Neck Surgery (Y.A., D.R.G.), Neurology and Neurosurgery (D.R.G.), and Ophthalmology (D.R.G.), School of Medicine, Johns Hopkins University, Baltimore, MD; Vestibular Disorders Association (S.B.), Portland, OR; Department of Otolaryngology (M.L.B., P.G., D.M.), Vanderbilt Medical Center, Nashville, TN; Shohet Ear Associates Medical Group (I.K.D.), Newport Beach, CA; Department of Neurology (I.G.O.), The Ohio State University Medical Center, Columbus; Department of Neurology (I.K.R.), Columbia University Medical Center/New York Presbyterian Hospital, New York; Head and Neck Institute (E.W.), Cleveland Clinic, OH; Division of Audiology, Department of Otorhinolaryngology (D.A.Z.), Mayo Clinical College of Medicine, Jacksonville, FL; American Academy of Neurology (A.B.), Minneapolis, MN; and Department of Neurology (A.M.S.), University of Massachusetts Medical School-Baystate Health, Springfield.

This special article is published simultaneously in Otolaryngology-Head and Neck Surgery and Neurology ${ }^{\circledR}$. Otolaryngology-Head and Neck Surgery's Editor-in-Chief managed peer review of the article, with each journal's Editor-in-Chief providing one peer reviewer.

Go to Neurology.org/N for full disclosures. Funding information and disclosures deemed relevant by the authors, if any, are provided at the end of the article. 


\section{Glossary}

AAN = American Academy of Neurology; AANI = American Academy of Neurology Institute; AAO-HNSF = American Academy of Otolaryngology-Head and Neck Surgery; BPPV = benign paroxysmal positional vertigo; CMS = Centers for Medicare and Medicaid Services; CRP = canalith repositioning procedure; MIPS = Merit-based Incentive Payment System; PROM = patient-reported outcome measure.

While unilateral and bilateral vestibular hypofunction may be the result of many conditions, the impairment itself, independent of the cause, should be addressed by a referral to vestibular rehabilitation for patients with chronic unilateral and bilateral vestibular hypofunction, according to recent guidelines. ${ }^{6}$ However, practice variations exist in that regard. ${ }^{7-9}$

BPPV accounts for approximately $8 \%$ of individuals with moderate or severe dizziness or vertigo. ${ }^{10}$ These patients can be evaluated in various care settings (primary care clinic, emergency department, otolaryngology, or neurology clinics). Although it is well-known that the Dix-Hallpike maneuver can be used to diagnose BPPV with a high degree of accuracy, there is a great variability in its usage. In interviews with emergency department physicians, barriers to use of the maneuver included prior negative experiences or forgetting how to perform it, as well as reliance on patient history to diagnose BPPV or misattributing the patterns of nystagmus observed during the maneuver. ${ }^{11}$ Even when the Dix-Hallpike maneuver is properly performed and the diagnosis is made, patients are not always treated according to the current standard of care as expressed in the recent clinical practice guideline from the AAO-HNSF. ${ }^{10,12}$ Despite the known efficacy of the CRP, it is most likely underutilized. According to Kerber, ${ }^{13}<10 \%$ of affected patients receive treatment, which results in suboptimal care.

In addition, the work group noted that there are opportunities to reduce the use of vestibular testing, imaging, and antihistamine and benzodiazepine use for patients with BPPV. Phillips et al. ${ }^{14}$ estimated that referrals for vestibular testing could be reduced by $9 \%$ by the routine use of Dix-Hallpike and by obtaining a complete medical history. A study by Grill et al. indicated that $70 \%$ of patients with BPPV receive MRI scanning, ${ }^{15}$ and there remains opportunity to reduce the use of imaging. The frequent use of neuroimaging indicates a gap in diagnosis skills of vertigo and may correlate to misdiagnosis-related harm. ${ }^{16}$ There is evidence supporting a potential increase of cognitive impairment and fall risk for patients prescribed benzodiazepines and antihistamines. ${ }^{12}$

\section{Methods}

The AANI and AAO-HNSF utilized a modified pilot measure development process for this project. Details of the American

\section{$\oplus$ Supplemental Data}

Full measurement set:

NPub.org/b5phte
Academy of Neurology Institute (AANI)'s full measure development process are available online. ${ }^{17}$ The work group included providers from audiology, otolaryngology, neuro-otology, and neurology as well as patients from advocacy organizations to ensure that measures developed included input from all members of the health care team and other relevant stakeholders. All members are required to disclose relationships with industry and other entities to avoid actual, potential, or perceived conflicts of interest. Individuals were instructed to abstain from voting on individual measure concepts if a conflict was present.

At the start of the project, existing guidelines, measures, and evidence were identified. A comprehensive literature search was conducted by a medical librarian, identifying 2,483 abstracts relevant to the topic. Following review, 5 guidelines were located, serving the basis of the evidence for measure development. The measure development process involved work group members anonymously ranking the initial 21 proposed concepts to winnow out concepts that lacked evidence, feasibility, or effect on care. Fourteen concepts were then reviewed and rated by work group members on the strength of evidence, ability to collect data without burden, and demonstrated link from process to improved outcomes. This resulted in the work group advancing 6 concepts for discussion. During work group discussions, numerators, denominators, exclusion criteria, and evidence were discussed and edited prior to holding a vote on each individual concept. The work group reached consensus on 5 measures to be developed prior to a 21-day public comment. Following public comment, these measures were further refined. Following response to each comment, the work group approved the measurement set, which was then approved by the AANI and AAO-HNSF Board of Directors.

\section{Results}

The work group approved 5 measures (table). Full measurement specifications are available at aan.com/policy-andguidelines/quality/quality-measures2/quality-measures/ and in appendix e-1 (links.lww.com/WNL/A678).

\section{Quality of life for patients with neuro- otology disorders}

The work group developed an outcome measure comparing the first and last quality-of-life scores collected in a calendar year for patients with neuro-otology conditions. One of the primary goals in health care is to improve the lives of our patients. This includes addressing issues that directly affect their quality of life. PROMs capture how a patient feels he or 
Table Neuro-otology quality measurement set ${ }^{\mathrm{a}}$

\begin{tabular}{|c|c|c|}
\hline Title & Numerator & Denominator \\
\hline $\begin{array}{l}\text { Quality of life for patients with } \\
\text { neuro-otology disorders }\end{array}$ & $\begin{array}{l}\text { Patients with age-appropriate quality of life assessment }{ }^{\mathrm{b}} \\
\text { whose most recent scores }{ }^{\mathrm{b}} \text { were maintained or improved } \\
\text { on the same age-appropriate quality of life assessment } \\
\text { administered twice during the measurement period }\end{array}$ & $\begin{array}{l}\text { Patients aged } \geq 18 \text { years with neuro-otology-specific } \\
\text { diagnosis (see code descriptions) seen at least } 2 \\
\text { times during the measurement period }\end{array}$ \\
\hline $\begin{array}{l}\text { Vestibular rehabilitation for } \\
\text { unilateral or bilateral vestibular } \\
\text { hypofunction }\end{array}$ & $\begin{array}{l}\text { Patients with an order for a referral to physical therapy } \\
\text { or occupational therapy for vestibular rehabilitation or } \\
\text { prescription for vestibular rehabilitation or } \\
\text { documentation that vestibular rehabilitation was } \\
\text { recommended or documentation that vestibular } \\
\text { rehabilitation was provided }\end{array}$ & $\begin{array}{l}\text { Patients diagnosed with unilateral or bilateral } \\
\text { vestibular hypofunction }\end{array}$ \\
\hline $\begin{array}{l}\text { Dix-Hallpike maneuver performed } \\
\text { for patients with BPPV }\end{array}$ & Patients who had a Dix-Hallpike maneuver performed & Patients diagnosed with BPPV \\
\hline $\begin{array}{l}\text { Canalith repositioning procedure } \\
\text { performed for patients with } \\
\text { posterior canal BPPV }\end{array}$ & $\begin{array}{l}\text { Therapeutic CRP performed or referral for physical } \\
\text { therapy or to a provider who can perform CRP }\end{array}$ & Patients diagnosed with posterior canal BPPV \\
\hline \multirow[t]{4}{*}{ Standard BPPV management } & $\begin{array}{l}\text { A. Patients with BPPV referred for vestibular testing by } \\
\text { the encounter provider; lower score is better }\end{array}$ & Patients diagnosed with BPPV \\
\hline & $\begin{array}{l}\text { B. Patients with BPPV referred, recommended, or ordered } \\
\text { a CT angiogram, CT, magnetic resonance angiogram, or } \\
\text { MRI by the encounter provider; lower score is better }\end{array}$ & Patients diagnosed with BPPV \\
\hline & $\begin{array}{l}\text { C. Patients with BPPV prescribed antihistamine or } \\
\text { benzodiazepine medication by the encounter provider; } \\
\text { lower score is better }\end{array}$ & Patients diagnosed with BPPV \\
\hline & D. Total patient performance on the 3 above components & Patients diagnosed with BPPV \\
\hline \multicolumn{3}{|c|}{$\begin{array}{l}\text { Abbreviations: BPPV = benign paroxysmal positional vertigo; CRP = canalith repositioning procedure. } \\
\text { a These measures were approved by the work group. There is no requirement that all measures in the measurement set be used. Providers are encouraged to } \\
\text { identify the } 1 \text { or } 2 \text { measures that would be most meaningful for their patient populations and to implement these measures to drive performance } \\
\text { improvement in practice. The work group strongly suggests that all providers screen for falls using the American Academy of Neurology's Universal Neurology } \\
\text { Falls Outcome and Plan of Care Measure. } \\
\text { b See full measure specifications for definitions. }\end{array}$} \\
\hline
\end{tabular}

she is doing using a validated tool, and they have been demonstrated to be feasible to collect for neurology. ${ }^{18}$ There is a need for quality measures that allow a clinician to determine if he or she is addressing patients' complaints adequately, using PROMs. The work group provided a list of multiple tools to meet the measure, which allows providers and systems to identify the tool that can be easily integrated into their practice, without major disruption of the clinic flow. The list is finite to allow implementation into registry and accountability programs. These tools will be revisited in future updates. The work group acknowledges that the available quality of life PROMs have an unclear effect on patient outcomes for this patient population. However, collection via registries will initiate pilot studies examining this issue. The measure will not be implemented as a CMS MIPS measure without testing data.

\section{Vestibular rehabilitation for unilateral or bilateral vestibular hypofunction}

The measure captures the percentage of patients diagnosed with unilateral or bilateral vestibular hypofunction who were referred, prescribed, recommended for, or received vestibular rehabilitation. The work group noted that, due to limited availability of vestibular rehabilitation services in certain areas of the United States, alternatives such as physical therapy or occupational therapy could be used to meet the measure and not penalize providers with limited access.

\section{Dix-Hallpike maneuver performed for patients with BPPV}

The work group discussed the best way to ensure proper diagnosis of BPPV. The vast majority of patients with BPPV can be quickly and easily diagnosed in the office using the DixHallpike maneuver (along with an appropriate history). ${ }^{12}$ To ensure proper diagnosis, a process measure assessing patients with BPPV who had a Dix-Hallpike maneuver performed was created. The measure has multiple exclusions for the denominator, including those who refuse the procedure, are unable to lie flat, have cervical spinal disease or severe atherosclerotic disease, are unable to be seated in an examination chair, or have a history of BPPV without current positional dizziness/vertigo.

\section{CRP performed for patients with posterior canal BPPV}

CRP involves moving the patient through specific body positions designed to relocate dislodged particles within the inner ear for the purpose of relieving symptoms of BPPV. Strong evidence supports use of CRP as an initial therapy for posterior canal BPPV. ${ }^{12}$ The measure is 
intended to increase use of CRP as first-line treatment. Multiple exclusions exist for the measure to address those who decline CRP, have cervical spine disease or severe atherosclerotic disease, are unable to lie flat, or are unable to be seated in an examination chair.

\section{Standard BPPV management}

The AAO-HNSF clinical practice guideline supports limited vestibular testing, benzodiazepine and antihistamine use, and imaging for patients with BPPV. ${ }^{12}$ This measure is intended to reduce vestibular testing, inappropriate imaging, and medication use. A lower score is indicative of better quality. The measure is intended to focus on typical patients with BPPV, but the work group realizes that there may be extraordinary cases (atypical vertigo, vertical nystagmus on Dix-Hallpike) where these interventions are warranted. As a result, multiple exclusions were created. Even with the exclusions, perfect (0\%) performance is not expected.

The work group discussed development of an outcome measure for BPPV but did not approve it for public comment, noting feasibility concerns. Specifically, many patients with BPPV who are successfully treated are lost to further follow-up, and their data are lost to providers. In addition, there is no uniform quantification of the resolution of symptoms. This concept will be revisited during future updates of the measurement set, which occur at a minimum every 3 years. Advances in electronic health record technology may lead to this concept's feasibility in future updates.

The work group discussed but did not develop a falls measure, noting a measure in development by the AANI Universal Neurology Work Group. Providers and systems are encouraged to use this measure to supplement the measurement of falls in their patient populations.

\section{Implications for practice}

These measures are intended for individual providers, practices, and systems and will provide needed tools to drive performance improvement in practice. There is no requirement that providers use every measure in the set. Providers are encouraged to identify the 1 or 2 measures that would be most meaningful for their patient populations and implement these measures to drive performance improvement in practice.

Select measures will be submitted for consideration in the AANI's Axon Registry and AAO-HNSF's Reg-ent registry, which are proving useful tools for providers to drive performance improvement in practice while meeting CMS MIPS requirements. It is anticipated that once testing data have been obtained, measures may be submitted for consideration in the CMS MIPS. In addition, select private payers may utilize measures to track provider performance. It is important that providers have access to neuro-otology-specific measures developed by multidisciplinary treatment team members in these systems to ensure that performance measures are meaningful to providers and patients.

\section{Author contributions}

Habib Rizk: contributed to acquisition of data, analysis and/or interpretation of data, drafting/revising the manuscript, critical revisions of the manuscript for important intellectual content, final approval. Yuri Agrawal: contributed to acquisition of data, analysis and/or interpretation of data, critical revisions of the manuscript for important intellectual content, final approval. Susan Barthel: contributed to acquisition of data, analysis and/ or interpretation of data, critical revisions of the manuscript for important intellectual content, final approval. Marc L. Bennett: contributed to acquisition of data, analysis and/or interpretation of data, critical revisions of the manuscript for important intellectual content, final approval. Joni K. Doherty: contributed to acquisition of data, analysis and/or interpretation of data, critical revisions of the manuscript for important intellectual content, final approval. Patricia Gerend: contributed to acquisition of data, analysis and/or interpretation of data, critical revisions of the manuscript for important intellectual content, final approval. Daniel R. Gold: contributed to acquisition of data, analysis and/or interpretation of data, critical revisions of the manuscript for important intellectual content, final approval. David Morrill: contributed to acquisition of data, analysis and/ or interpretation of data, critical revisions of the manuscript for important intellectual content, final approval. John G. Oas: contributed to acquisition of data, analysis and/or interpretation of data, critical revisions of the manuscript for important intellectual content, final approval. J. Kirk Roberts: contributed to acquisition of data, analysis and/or interpretation of data, critical revisions of the manuscript for important intellectual content, final approval. Erika Woodson: contributed to acquisition of data, analysis and/or interpretation of data, critical revisions of the manuscript for important intellectual content, final approval. David A. Zapala: contributed to acquisition of data, analysis and/or interpretation of data, critical revisions of the manuscript for important intellectual content, final approval. Amy Bennett: contributed to concept and design, acquisition of data, analysis and/or interpretation of data, drafting/revising the manuscript, critical revisions of the manuscript for important intellectual content, supervision including responsibility for conduct and final approval. Anant M. Shenoy: contributed to concept and design, acquisition of data, analysis and/or interpretation of data, drafting/revising the manuscript, critical revisions of the manuscript for important intellectual content, supervision including responsibility for conduct and final approval.

\section{Study funding}

No targeted funding reported.

\section{Disclosure}

Amy Bennett is an employee of the American Academy of Neurology. Joni K. Doherty is a Clinical Advisory Board member for Frequency Therapeutics, Inc. Patricia Gerend receives a pension from Roche. Go to Neurology.org/N for full disclosures. 


\section{Disclaimer}

This special article is published simultaneously in Neurology ${ }^{\circledR}$ and Otolaryngology-Head and Neck Surgery. OtolaryngologyHead and Neck Surgery's editor in chief managed peer review of the article, with each journal's editor in chief providing one peer reviewer.

\section{Publication history}

Received by Neurology July 23, 2018. Accepted in final form July 23, 2018.

\section{References}

1. National Institute on Deafness and Other Communication Disorders. A Report of the Task Force on the National Strategic Research Plan. Bethesda, MD: National Institutes of Health; 1989.

2. Bigelow R, Semenov YR, du Lac S, Hoffman HJ, Agrawal Y. Vestibular vertigo and comorbid cognitive and psychiatric impairment: The 2008 National Health Interview Survey. J Neurol Neurosurg Psychiatry 2016;87:367-372.

3. van der Zaag-Loonen HJ, van Leeuwen RB. Dizziness causes absence from work. Acta Neurol Belg 2015;115:345-349.

4. Neuhauser HK, Radtke A, von Brevern M, et al. Burden of dizziness and vertigo in the community. Arch Intern Med 2008;168:2118-2124.

5. Centers for Medicare and Medicaid Services. CMS Quality Measure Development Plan: Supporting the Transition to the Merit-Based Incentive Payment System (MIPS) and Alternative Payment Models (APMs). Baltimore, MD: Centers for Medicare and Medicaid Services; 2016.

6. Hall CD, Herdman SJ, Whitney SL, et al. Vestibular rehabilitation for peripheral vestibular hypofunction: An evidence-based clinical practice guideline: From the
American Physical Therapy Association Neurology Section. J Neurol Phys Ther 2016;40:124-155.

7. Bush ML, Dougherty W. Assessment of vestibular rehabilitation therapy training and practice patterns. J Community Health 2015;40:802-807.

8. Lee A, Jones G, Corcoran J, et al. A UK hospital based multidisciplinary balance clinic run by allied health professionals: first year results. J Laryngol Otol 2011;125:661-667.

9. Cohen HS, Gottshall KR, Grazino M, Malmstrom EM, Sharpe MH. International survey of vestibular rehabilitation therapists by the Barany Society Ad Hoc Committee on Vestibular Rehabilitation Therapy. J Vestib Res 2009;19: $15-20$

10. von Brevern M, Radtke A, Lezius F. Epidemiology of benign paroxysmal positional vertigo: a population based study. J Neurol Neurosurg Psychiatry 2007;78: $710-715$.

11. Kerber KA, Forman J, Damschroder L, et al. Barriers and facilitators to ED physician use of the test and treatment for BPPV. Neurol Clin Pract 2017;7:214-224.

12. Bhattacharyya N, Gubbels SP, Scwartz SR, et al. Clinical practice guideline: benign paroxysmal positional vertigo (update) executive summary. Otolaryngol Head Neck Surg 2017;156:S1-S47.

13. Kerber KA. Benign paroxysmal positional vertigo: opportunities squandered. Ann NY Acad Sci 2015;1343:106-112.

14. Phillips JS, FitzGerald JE, Bath AP. The role of the vestibular assessment. J Laryngol Otol 2009; $123: 1212-1215$

15. Grill E, Strupp M, Müller M, et al. Health services utilization of patients with vertigo in primary care: a retrospective cohort study. J Neurol 2014;261:1492-1498.

16. Liberman AL, Newman-Toker D. Symptom-Disease Pair Analysis of Diagnostic Error (SPADE): a conceptual framework and methodological approach for unearthing misdiagnosis-related harms using big data. BMJ Qual Saf 2018;27:557-566.

17. Quality and Safety Subcommittee. American Academy of Neurology quality measurement manual 2017 update. Available at: aan.com/policy-and-guidelines/quality/qualitymeasures 2 /how-measures-are-developed/. Published in January 2018. Accessed July 25, 2018.

18. Moura LMVR, Schwamm E, Moura V Jr, et al. Feasibility of the collection of patientreported outcomes in an ambulatory neurology clinic. Neurology 2016;87:1-8.

\section{Add Your Voice! Apply for 2019 Neurology on the Hill}

The AAN continues to fight for common sense health care reform that promotes neurology and protects your patients. Add your voice to the conversation at Neurology on the Hill from February 25 to 26, 2019, and help educate members of Congress so we can address critical health policy problems together. If selected, you will receive training to bring you up-to-date on key issues. Then, you will go to Capitol Hill for face-to-face meetings with congressional members and their staffs.

Learn more and apply by November 2, 2018, at AAN.com/view/NOH.

\section{Visit the Neurology ${ }^{\circledR}$ Website at Neurology.org/N}

- More article-based content on home pages

- Streamlined menus and navigation

- Enhanced blog sections for specialty areas

- Same experience on desktop, tablet, and mobile devices

- Audio summaries of current issues

- Improved article reading experience; links more evident (pdf, analytics, social media)

- Neurology ${ }^{\circledR}$ Clinical Practice initiative "Practice Current" global surveys will be accessible across sites

f Find Neurology ${ }^{\circledR}$ on Facebook: http://tinyurl.com/neurologyfan

Follow Neurology ${ }^{\circledR}$ on Twitter: https://twitter.com/GreenJournal 


\section{Neurology}

\section{Quality improvement in neurology: Neuro-otology quality measurement set}

Habib Rizk, Yuri Agrawal, Susan Barthel, et al.

Neurology 2018;91;697-701 Published Online before print August 31, 2018

DOI 10.1212/WNL.0000000000006217

This information is current as of August 31, 2018

\begin{tabular}{|c|c|}
\hline $\begin{array}{l}\text { Updated Information \& } \\
\text { Services }\end{array}$ & $\begin{array}{l}\text { including high resolution figures, can be found at: } \\
\text { http://n.neurology.org/content/91/15/697.full }\end{array}$ \\
\hline References & $\begin{array}{l}\text { This article cites } 15 \text { articles, } 5 \text { of which you can access for free at: } \\
\text { http://n.neurology.org/content/91/15/697.full\#ref-list-1 }\end{array}$ \\
\hline Citations & $\begin{array}{l}\text { This article has been cited by } 1 \text { HighWire-hosted articles: } \\
\text { http://n.neurology.org/content/91/15/697.full\#\#otherarticles }\end{array}$ \\
\hline Permissions \& Licensing & $\begin{array}{l}\text { Information about reproducing this article in parts (figures,tables) or in } \\
\text { its entirety can be found online at: } \\
\text { http://www.neurology.org/about/about_the_journal\#permissions }\end{array}$ \\
\hline Reprints & $\begin{array}{l}\text { Information about ordering reprints can be found online: } \\
\text { http://n.neurology.org/subscribers/advertise }\end{array}$ \\
\hline
\end{tabular}

Neurology ${ }^{\circledR}$ is the official journal of the American Academy of Neurology. Published continuously since 1951, it is now a weekly with 48 issues per year. Copyright (O 2018 American Academy of Neurology. All rights reserved. Print ISSN: 0028-3878. Online ISSN: 1526-632X.

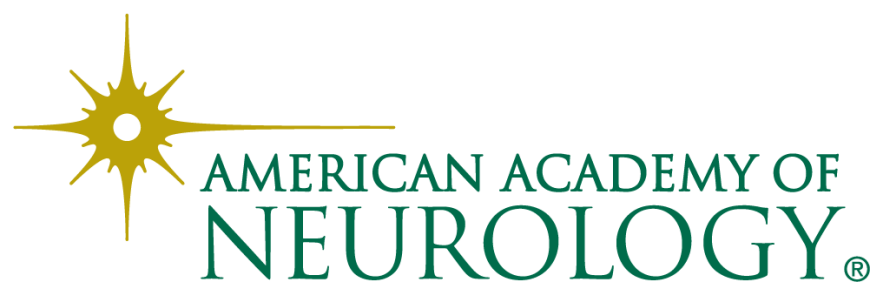

